\title{
Low-dose Clozapine-induced Seizure: A Case Report
}

\author{
Abdullah Bolu ${ }^{1}$, Süleyman Akarsu ${ }^{2}$, Erdal Pan ${ }^{1}$, Emre Aydemir $^{3}$, Taner Oznur ${ }^{4}$ \\ ${ }^{1}$ Aircrew's Health Research and Training Center, Eskişehir, ${ }^{2}$ Department of Psychiatry, Iskenderun Military Hospital, Hatay, ${ }^{3}$ Department of \\ Psychiatry, Beytepe Military Hospital, Ankara, ${ }^{4}$ Department of Psychiatry, Gülhane Military Medical Faculty, Ankara, Turkey
}

\begin{abstract}
Seizures are believed to be a dose-dependent side effect of clozapine. In this case report, we describe a patient who had tonic-clonic seizures after using a low dose clozapine who did not have any seizure risk. The 29-year-old male patient had been followed-up with a diagnosis of schizophrenia for about 5 years. When using clozapine $200 \mathrm{mg} /$ day he had a tonic-clonic seizure with bilateral diffuse epileptic activity in electroencephalography (EEG). In the literature, there are a few case reports about low-dose clozapine-induced seizure. Seizures were observed in our case with a low dose of clozapine (200 mg/day) making this case remarkable. EEG monitoring at regular intervals and examination of plasma levels of clozapine could be useful in preventing the development of seizures.
\end{abstract}

KEY WORDS: Clozapine; Adverse effects; Seizures; Safety.

\section{INTRODUCTION}

Clozapine is a serotonin-dopamine (5HT2A-D2) receptor antagonist and an atypical antipsychotics that is used successfully in the treatment of schizophrenia. Although clozapine is one of the most effective antipsychotics, it has life-threatening side effects. Agranulocytosis, bowel infarction, myocarditis, diabetes, sialorrhea, weight gain are common side effects of clozapine. ${ }^{1)}$ It can induce epileptic seizures and changes in electroencephalography (EEG)-patterns, and the incidence of seizures during treatment is $1.3 \%$ to $10 \%$, depending on dose. The incidence of EEG abnormalities induced by clozapine treatment range from $16 \%$ to $74 \%{ }^{2-9)}$ The risk of epileptic seizures at low doses is very low, but is assocated with dosage escalation and rapid dose titration. ${ }^{7)}$ Preexisting seizure disorders, neurological abnormalities, and the combination with epileptogenic medications are the other risk factors. ${ }^{10)}$ In this case report, a patient had tonic-clonic seizures after using low dose clozapine. The patient did not have any seizure risk. Physical or neurological disease was not presented.

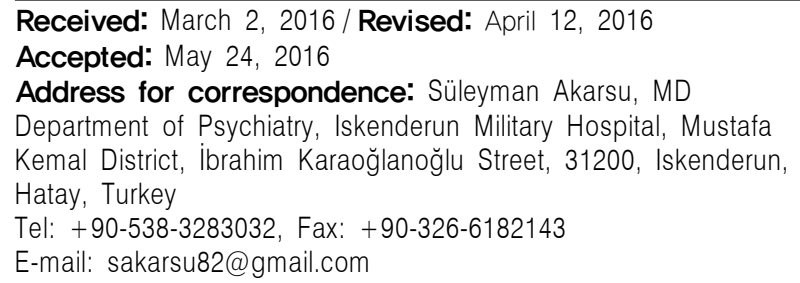

\section{CASE}

The 29-year-old male patient had been followed-up for schizophrenia for about 5 years. He had several symptoms including introversion, impaired social functioning, and unwillingness. He had used olanzapine and risperidone at standard doses and for an adequate period of time. In the process, auditory hallucinations and suicidal thoughts had occurred, and he had been hospitalized twice.

He was admitted to our department with positive symptoms two years ago. On the first hospital day, common blood cell count, routine biochemical tests, electrocardiogram and EEG were done. All test results were within normal limits. Clozapine ( $25 \mathrm{mg}$ /day) was started and showed inadequate response. Low dose titration up to $200 \mathrm{mg}$ /day was done within 4 weeks. Remission was achieved with $200 \mathrm{mg} /$ day clozapine.

At the third month of treatment, he had a tonic-clonic seizure witnessed by his mother. It lasted 30-40 seconds with a loss of consciousness, deadlock in the chin and urinary incontinence. The patient was in a state of confusion when he arrived the emergency room of our hospital. He had no epileptic seizures before and there was no history of epilepsy in first-degree relatives. There was no history of alcohol use, drug use or head trauma. His body weight was $71 \mathrm{~kg}$, waist circumference was 84 and body mass index was $23.2 \mathrm{~kg} / \mathrm{m}^{2}$. Blood biochemistry test results (fasting blood glucose levels of serum electrolytes, and re-

(a) This is an Open-Access article distributed under the terms of the Creative Commons Attribution Non-Commercial License (http://creativecommons.org/licenses/by-nc/4.0) which permits unrestricted non-commercial use, distribution, and reproduction in any medium, provided the original work is properly cited. 


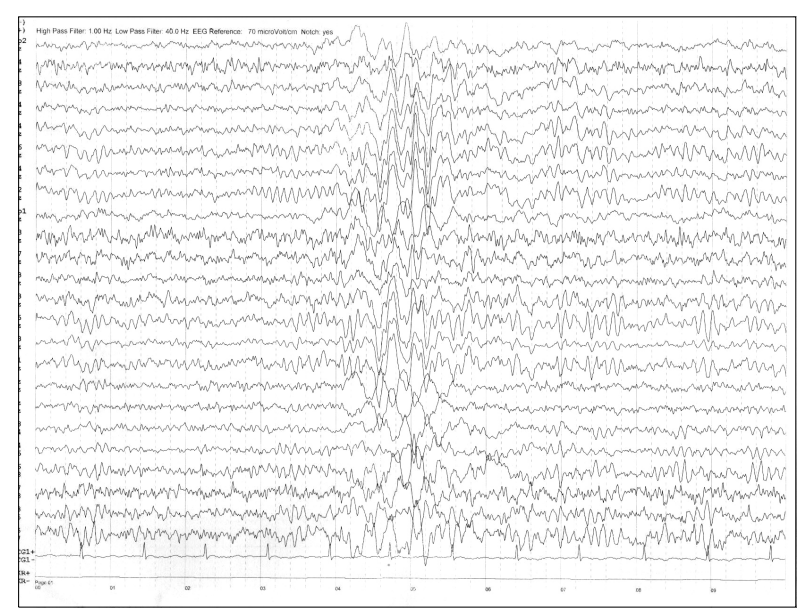

Fig. 1. Bilateral diffuse epileptic activity with $200 \mathrm{mg} /$ day clozapine use.

nal and liver function tests) were normal. Bilateral diffuse epileptic activity was detected at EEG (Fig. 1). The results of the investigations that were performed to rule out other causes of seizures (brain computerized tomography scan, brain magnetic resonance imaging) were normal. The seizure was considered to be triggered by clozapine, according to neurological consultation. Clozapine was reduced to $100 \mathrm{mg} /$ day, and valproic acid 1,000 mg/day was started. EEG performed at 2 weeks, and 4 months after the seizures showed no abnormality (Fig. 2). There was no change in the patient's weight. Seizures did not recur in the patient's follow-up and psychotic symptoms were under control. The patient has taken the same treatment until now and is in remission.

\section{DISCUSSION}

The mechanism lowering seizure threshold of clozapine is not clearly known. Different mechanisms are considered to be effective. According to the prominent hypothesis; mesolimbic structures are closely associated with seizure onset areas and clozapine inhibits D4 receptors on mesolimbic system and cortex. ${ }^{11)}$ It is thought that this situation causes high epileptogenicity of clozapine. ${ }^{7)}$ Other possible mechanisms are anticholinergic efficacy of clozapine (H1, Ach-Mus receptor blockade) and its effects on other receptor types such as gamma-aminobutyric acid A, nicotinic acetylcholine, glutamate $\mathrm{N}$-methyl-D-aspartate, serotonin 5-HT2A, and strychnine-sensitive glycine. ${ }^{4,12-16)}$ Increasing seizure threshold of clozapine is dosedependent. High-dose therapy (greater than or equal to $600 \mathrm{mg} /$ day) was associated with a greater risk of seizures ( $5 \%$ to $14 \%$ ) than medium (300 to $600 \mathrm{mg} /$ day; $2.7 \%$ to

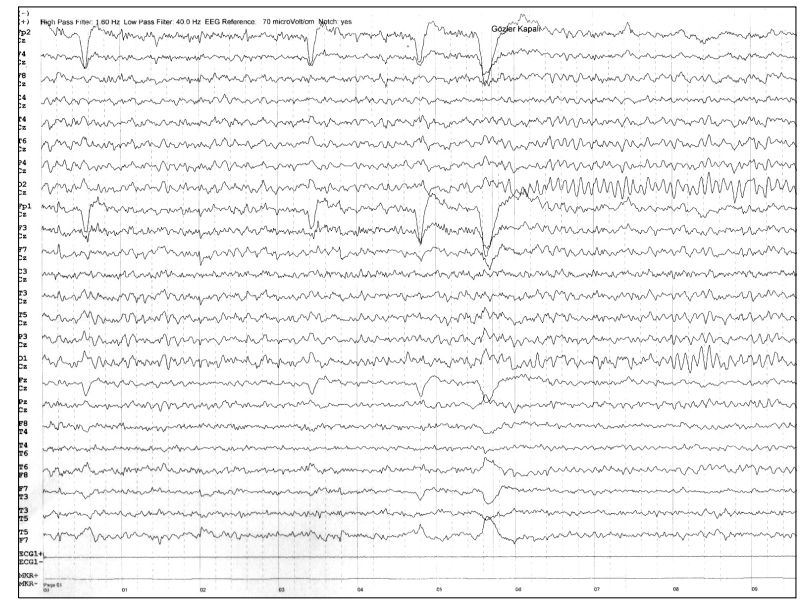

Fig. 2. No abnormality at the electroencephalography performed at 4 months after the seizures with $100 \mathrm{mg} /$ day clozapine and $1,000 \mathrm{mg} /$ day valproic acid use.

$4 \%$ ) or low doses (less than $300 \mathrm{mg} /$ day; $0.6 \%$ to $2 \%$ ). ${ }^{17-20)}$ Rapid upward titration may also increase seizure risk.

A seizure at $200 \mathrm{mg} /$ day is remarkable. In the literature, there are a few case reports with inaccessible content about low-dose clozapine-induced seizure. ${ }^{21,22)}$ A case of tonic-clonic seizures after using $300 \mathrm{mg} /$ day of clozapine has been reported. ${ }^{23)}$ In a study of 26 patients, EEG abnormalities were observed with average $305.0 \pm 131.7 \mathrm{mg}$ dose in 10 patients. Clozapine dose was $200 \mathrm{mg} /$ day in 3 of these 10 patients. ${ }^{4)}$ Having seizures despite low dose clozapine suggests that there may be other risk factors than dose and titration rate for seizures. Some factors such as high doses of antipsychotic drugs, rapid dose changes, abrupt discontinuation of medication, sedative properties of drugs, the presence of organic mental disorders, the presence of previous epilepsy or EEG abnormalities, a history of head trauma, family history of epilepsy and alcohol withdrawal have been reported to increase the risk of seizures. ${ }^{9,24)}$ An epileptic seizure had developed in our case although he had no these risk factors.

Welch et $a{ }^{2}{ }^{2)}$ suggested that the EEG is a sensitive indicator of clozapine toxicity. EEG abnormalities such as spikes and sharp waves indicate a increased risk of convulsions. Other studies show that EEG abnormalities may be present without any association with clinical seizures. ${ }^{25-27)}$ In this case, while EEG pathology was not detected before starting clozapine, no EEG monitoring was performed while using the drug. The relationship between incidence of seizure and EEG abnormalities developed after starting clozapine use needs to be examined with more extensive prospective studies.

Plasma clozapine levels were not measured here. A 
strong relationship between clozapine dose and plasma level and clozapine-induced EEG abnormalities were described. However, no statistically significant relationship between dose and incidence of seizures has been detected, ${ }^{27,28)}$ and plasma levels of clozapine in some patients may be low despite the high-dose clozapine use. Clozapine plasma levels may be excessively reduced with smoking. After quitting smoking, a sudden rise in plasma clozapine level can be seen. Also, drugs interfering with cytochrome P450 1A2 may increase or decrease the plasma levels of clozapine. Thus, therapeutic drug monitoring of clozapine has been suggested to predict the onset of seizures. ${ }^{27,29)}$ In case of developing epileptic seizures during clozapine treatment, clozapine dose reduction, changing clozapine with another antipsychotic drug or adding antiepileptics to the treatment are recommended. ${ }^{30)} \mathrm{We}$ did not change the clozapine treatment of our case because of previously insufficient response to the antipsychotic treatment except clozapine. We thought it was more appropriate to make seizure prophylaxis with antiepileptic treatment. We started sodium valproate as standard dose level for the prevention of seizures occurring due to the use of clozapine. ${ }^{7}$ Antiepileptic prophylaxis in patients using clozapine without clinical seizures can be performed in such cases at a certain clozapine dose or plasma level $(>500 \mu \mathrm{g} / \mathrm{L})$ or the appearance of clear epileptiform discharges on EEG. ${ }^{27,28)}$

Clozapine has serious side effects and to monitor patients on clozapine is advisable. ${ }^{31)}$ EEG monitoring at regular intervals and examining plasma levels of clozapine would be useful for preventing the development of seizures. However, plasma level of clozapine or electroencephalogram findings may be insufficient to predict the incidence of seizures. ${ }^{32,33)}$ Epileptic seizures can be seen even in very low risk situations such as our patient. Using drugs to reduce the epileptic threshold with clozapine should be avoided. Also raising awareness in the families of patients using clozapine is important. When a first seizure occurs, reducing the dosage of clozapine or employing an alternative antipsychotic agent should be preferred. If a second seizure occurs, an anticonvulsant drug should be started. $^{32)}$

\section{REFERENCES}

1. Si TM, Zhang YS, Shu L, Li KQ, Liu XH, Mei QY, et al. Use of clozapine for the treatment of schizophrenia: findings of the 2006 research on the china psychotropic prescription studies. Clin Psychopharmacol Neurosci 2012;10:99-104.

2. Welch J, Manschreck T, Redmond D. Clozapine-induced seizures and EEG changes. J Neuropsychiatry Clin Neurosci 1994;6:250-256.
3. Naber D, Leppig M, Grohmann R, Hippius H. Efficacy and adverse effects of clozapine in the treatment of schizophrenia and tardive dyskinesia--a retrospective study of 387 patients. Psychopharmacology (Berl) 1989;99 Suppl:S73-S76.

4. Kikuchi YS, Sato W, Ataka K, Yagisawa K, Omori Y, Kanbayashi T, et al. Clozapine-induced seizures, electroencephalography abnormalities, and clinical responses in Japanese patients with schizophrenia. Neuropsychiatr Dis Treat 2014;10:1973-1978.

5. Schuld A, Kühn M, Haack M, Kraus T, Hinze-Selch D, Lechner $\mathrm{C}$, et al. A comparison of the effects of clozapine and olanzapine on the EEG in patients with schizophrenia. Pharmacopsychiatry 2000;33:109-111.

6. Landry P. Gabapentin for clozapine-related seizures. Am J Psychiatry 2001;158:1930-1931.

7. Devinsky O, Pacia SV. Seizures during clozapine therapy. J Clin Psychiatry 1994;55 Suppl B:153-156.

8. Günther W, Baghai T, Naber D, Spatz R, Hippius H. EEG alterations and seizures during treatment with clozapine. A retrospective study of 283 patients. Pharmacopsychiatry 1993;26:69-74.

9. Centorrino F, Price BH, Tuttle M, Bahk WM, Hennen J, Albert MJ, et al. EEG abnormalities during treatment with typical and atypical antipsychotics. Am J Psychiatry 2002; 159:109-115.

10. Toth P, Frankenburg FR. Clozapine and seizures: a review. Can J Psychiatry 1994;39:236-238.

11. Mansour A, Meador-Woodruff JH, Burke S, Bunzow JR, Akil H, Van Tol HHM, et al. Differential distribution of D2 and D4 dopamine receptor $m R N A$ s in rat brain: An in situ hybridization study. Soc Neurosci Abstr 1991;17:599.

12. Arvanov VL, Wang RY. Clozapine, but not haloperidol, prevents the functional hyperactivity of $\mathrm{N}$-methyl-D-aspartate receptors in rat cortical neurons induced by subchronic administration of phencyclidine. J Pharmacol Exp Ther 1999;289:1000-1006.

13. Liu Y, Hu C, Tang Y, Chen J, Dong M, Song T, et al. Clozapine inhibits strychnine-sensitive glycine receptors in rat hippocampal neurons. Brain Res 2009;1278:27-33.

14. Singhal SK, Zhang L, Morales M, Oz M. Antipsychotic clozapine inhibits the function of alpha7-nicotinic acetylcholine receptors. Neuropharmacology 2007;52:387-394.

15. Squires RF, Saederup E. Clozapine and several other antipsychotic/antidepressant drugs preferentially block the same 'core' fraction of GABA(A) receptors. Neurochem Res 1998;23:1283-1290.

16. Steward LJ, Kennedy MD, Morris BJ, Pratt JA. The atypical antipsychotic drug clozapine enhances chronic PCP-induced regulation of prefrontal cortex 5-HT2A receptors. Neuropharmacology 2004;47:527-537.

17. Ereshefsky L, Watanabe MD, Tran-Johnson TK. Clozapine: an atypical antipsychotic agent. Clin Pharm 1989;8:691709 .

18. Haller E, Binder RL. Clozapine and seizures. Am J Psychiatry 1990;147:1069-1071.

19. Lieberman JA, Kane JM, Johns CA. Clozapine: guidelines for clinical management. J Clin Psychiatry 1989;50:329338.

20. Hedges DW, Jeppson KG. New-onset seizure associated with quetiapine and olanzapine. Ann Pharmacother 2002; 36:437-439.

21. Ravasia S, Dickson RA. Seizure on low-dose clozapine. Can J Psychiatry 1998;43:420.

22. Thomas P, Goudemand M. Seizure with low doses of clozapine. Am J Psychiatry 1992;149:138-139. 
23. Newton-Howes G. The low down: clinical response complicated by tonic-clonic seizures on low dose clozapine. Aust N Z J Psychiatry 2009;43:979-980.

24. Güleç G, Kılıç RY. Seizure associated with olanzapine: case report. Bull Clin Psychopharmacol (Turk) 2007;17:134-137.

25. Risby ED, Epstein CM, Jewart RD, Nguyen BV, Morgan WN, Risch SC, et al. Clozapine-induced EEG abnormalities and clinical response to clozapine. J Neuropsychiatry Clin Neurosci 1995;7:466-470.

26. Silvestri RC, Bromfield EB, Khoshbin S. Clozapine-induced seizures and EEG abnormalities in ambulatory psychiatric patients. Ann Pharmacother 1998;32:1147-1151.

27. Goyal N, Praharaj SK, Desarkar P, Nizamie H. Electroencephalographic abnormalities in clozapine-treated patients: A cross-sectional study. Psychiatry Investig 2011;8:372-376.

28. Varma S, Bishara D, Besag FM, Taylor D. Clozapine- related EEG changes and seizures: dose and plasma-level relationships. Ther Adv Psychopharmacol 2011;1:47-66.

29. Greenwood-Smith C, Lubman DI, Castle DJ. Serum clozapine levels: a review of their clinical utility. J Psychopharmacol 2003; 17:234-238.

30. Eren I. Klozapin kullanımına bağll gelișen epileptik nöbet ve nöbetin Gabapentin ile tedavisi: Olgu sunumu. Klinik Psikiyatri 2003;6:119-122. Turkish.

31. Kar N, Barreto S, Chandavarkar R. Clozapine monitoring in clinical practice: beyond the mandatory requirement. Clin Psychopharmacol Neurosci 2016;14:323-329.

32. Wong J, Delva N. Clozapine-induced seizures: recognition and treatment. Can J Psychiatry 2007;52:457-463.

33. Caetano D. Use of anticonvulsants as prophylaxis for seizures in patients on clozapine. Australas Psychiatry 2014;22:78-83. 